\title{
The bionomics of the malaria vector Anopheles rufipes Gough, 1910 and its susceptibility to deltamethrin insecticide in North Cameroon
}

Parfait H. Awono-Ambene ${ }^{1}$, Josiane Etang ${ }^{1,2}$, Christophe Antonio-Nkondjio ${ }^{1}$, Cyrille Ndo ${ }^{1,2}$, Wolfgang Ekoko Eyisap ${ }^{3}$, Michael C. Piameu ${ }^{4}$, Elysée S. Mandeng ${ }^{5}$, Ranaise L. Mbakop ${ }^{5}$, Jean Claude Toto ${ }^{1}$, Salomon Patchoke ${ }^{6}$, Abraham P. Mnzava ${ }^{7}$, Tessa B. Knox ${ }^{8}$, Martin Donnelly ${ }^{9}$, Etienne Fondjo ${ }^{6}$ and Jude D. Bigoga ${ }^{10^{*}}$

\begin{abstract}
Background: Following the recent discovery of the role of Anopheles rufipes Gough, 1910 in human malaria transmission in the northern savannah of Cameroon, we report here additional information on its feeding and resting habits and its susceptibility to the pyrethroid insecticide deltamethrin.

Methods: From 2011 to 2015, mosquito samples were collected in 38 locations across Garoua, Mayo Oulo and Pitoa health districts in North Cameroon. Adult anophelines collected using outdoor clay pots, window exit traps and indoor spray catches were checked for feeding status, blood meal origin and Plasmodium circumsporozoite protein. The susceptibility of field-collected An. rufipes to deltamethrin was assessed using WHO standard procedures.

Results: Of 9327 adult Anopheles collected in the 38 study sites, An. rufipes (6.5\%) was overall the fifth most abundant malaria vector species following An. arabiensis (52.4\%), An. funestus (s.l.) (20.8\%), An. coluzzii (12.6\%) and An. gambiae (6.8\%). This species was found outdoors (51.2\%) or entering houses (48.8\%) in 35 suburban and rural locations, together with main vector species. Apart from human blood with index of 37\%, An. rufipes also fed on animals including cows (52\%), sheep (49\%), pigs (16\%), chickens (2\%) and horses (1\%). The overall parasite infection rate of this species was $0.4 \%$ based on the detection of $P$. falciparum circumsporozoite proteins in two of 517 specimens tested. Among the 21 An. rufipes populations assessed for deltamethrin susceptibility, seven populations were classified as "susceptible" (mortality $\geq 98 \%$ ), ten as "probable resistant" with a mortality range of 90-97\% and four as "resistant" with a mortality range of $80-89 \%$.

Conclusions: This study revealed changeable resting and feeding behaviour of An. rufipes, as well as further evidence on its ability to carry human malaria parasites in North Cameroon. Besides, this species is developing physiological resistance to deltamethrin insecticide which is used in treated nets and agriculture throughout the country, and should be regarded as one of potential targets for the control of residual malaria parasite transmission in Africa.
\end{abstract}

Keywords: Malaria vector, Anopheles rufipes, Bionomics, Deltamethrin susceptibility

\footnotetext{
* Correspondence: jbigoga@gmail.com

${ }^{10}$ National Reference Unit for Vector Control, The Biotechnology Center,

University of Yaoundé I, P.O. Box 3851-Messa, Yaoundé, Cameroon

Full list of author information is available at the end of the article
} 


\section{Background}

The Anopheles fauna of the Afrotropical region has about 150 species, and almost 20 species are involved in the transmission of malaria parasites to humans [1]. Between 2010 and 2015, there was a 13\% reduction of the population at risk of malaria in subSaharan Africa. However, most cases (90\%) and deaths (92\%) still occur in the WHO African Region [2]. In Cameroon, the disease is endemic throughout the country, with some variations on the transmission intensity in specific areas such as highlands and Sahel. The estimated number of malaria cases in the country was almost 1.2 million cases in 2013 [3]. The vast majority of cases and related deaths are due to $P$. falciparum, with $P$. malariae and $P$. ovale species being of minor importance. Plasmodium falciparum malaria is responsible for $36 \%$ of outpatient consultation, $67 \%$ of childhood mortality and $48 \%$ of hospital admissions [4]. Various interventions such as targeted case management of vulnerable groups (children under 5) and mass prevention strategies mostly based on the general use of long-lasting insecticidal nets (LLINs) against vectors have contributed to significantly reduce the overall malaria prevalence from 46 . $3 \%$ in 2008 to $26.5 \%$ in 2013 [4]. However, this progress may be compromised by the risk of development of drug resistance in parasites and of vector resistance to insecticides.

Vector control is currently a key strategy to prevent malaria in Cameroon and other endemic countries. Six anopheline species also distributed across the African region are considered as main local vectors of human malaria parasites: Anopheles gambiae Giles, 1902; An. coluzzii Coetzee et al., 2013 (see [5]); An. funestus Giles, 1900; An. arabiensis Patton, 1905; An. nili Theobald, 1904; and An. moucheti Evans, 1925. Alongside these main vectors, several species of socalled "secondary vectors" contribute locally to continuous identified transmission of malaria [6-8]: An. paludis Theobald, 1900; An. carnevalei Brunhes et al., 1999 (see [9]); An. coustani Laveran, 1900; An. marshallii Theobald, 1903; An. ziemanni Gruenberg, 1902; An. pharoensis Theobald, 1901; An. hancocki Edwards, 1929; An. wellcomei Theobald, 1904; and An. ovengensis Awono-Ambene et al. 2004 (see [10]). The recent revision of the list of malaria vectors to include two additional species, An. ziemanni [11] and $A n$. rufipes [12], suggests that full assessment of potential malaria vectors across the country is needed. Several studies conducted in areas where LLINs are used in large scale have revealed deltamethrin resistance in An. gambiae (s.l.) and An. funestus populations [13-16]. With the intensification of use of insecticidal vector control interventions, the landscape of local malaria epidemiology and insecticide susceptibility may change. New vectors may be introduced or well established vectors may become scarce, potentially with an expansion of insecticide resistance to marginalized potential vector species. In fact, changes in vectorial capacity may also occur in some anopheline species previously known as non-competent malaria vector species, such as An. rufipes.

Anopheles rufipes Gough, 1910, which belongs to the subgenus Cellia and series Neocellia is mostly distributed in tropical savannas of the sub-Saharan region. Apart from this typical form, there is a darkform (Anopheles rufipes brousseri Edwards, 1929) also found in these areas [17]. In Cameroon, the typical form An. rufipes, is regularly found in mosquito collections from northern region [12]. Its larvae normally develop in various standing and open water pools (e.g. rice fields, stream pools) which are also typical aquatic habitats for immature stages of $A n$. gambiae (s.l.). In North Cameroon, main vector species belong to the An. gambiae complex, An. funestus (s.s.) and An. pharoensis [7], for which patterns of feeding and resting behavior, as well as the status of susceptibility to insecticides are increasingly documented [7, 13-16]. This region has a long history of pesticide utilization in agriculture and vectors have developed phenotypic resistance to DDT and pyrethroids, with multiple insecticide resistance mechanisms $[14,15,18]$. However, despite the abundance of An. rufipes in northern regions of Cameroon, very little attention has been given to this species bionomic as it was previously considered a non-competent malaria vector based on its zoophilic tendencies [17]. Following the recent publication of a cross-sectional survey on the role of this species in human malaria transmission in North Cameroon [12], we report further information on its feeding and resting habits, and first evaluation of its susceptibility to deltamethrin, the main pyrethroid insecticide of LLINs used in this area.

\section{Methods \\ Study period and sites}

Cross-sectional studies were conducted once each year during the rainy season (September to November) from 2011 to 2014 in 38 locations (clusters) belonging to three health districts (Garoua, Mayo Oulo and Pitoa) in the North region of Cameroon (Fig. 1). In the year 2015, the field survey was limited to larval collections and susceptibility tests on adults in different study sites. The three health districts are located in the tropical domain of the North region of Cameroon, and served as regional sentinel sites for monitoring of the efficacy of LLINs since the nationwide mass distribution of 2011. 


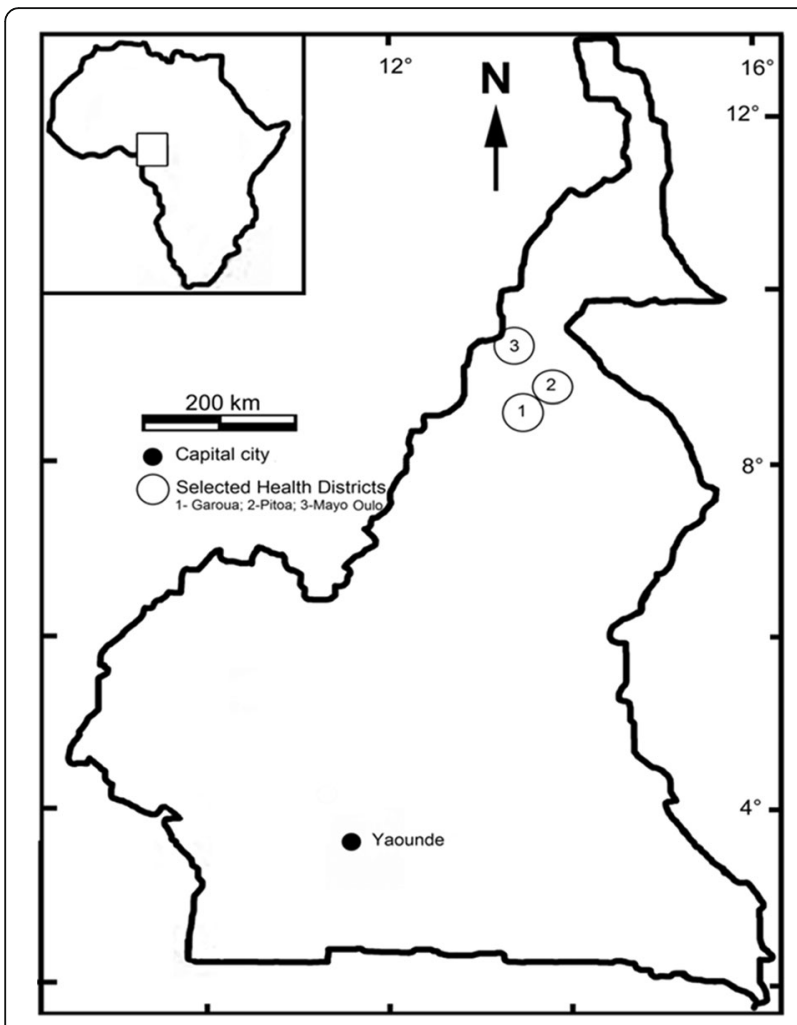

Fig. 1 Map of Cameroon showing the location of the three selected health districts

The full description of the selected health districts and their respective study sites has been made in previous reports $[12,19]$.

\section{Mosquito collections}

Mosquito collections were performed every year between September and November using the dipping technique for larval collections and three conventional adult mosquito sampling methods: outdoor clay pots (OCPs), window exit traps (WETs) and indoor spraying collections (ISCs) [20, 21]. The adult mosquito trapping methods were chosen to specifically target resting mosquitoes as they enter or leave the houses, and also when they rest outdoors [22].

OCPs used as outdoor shelters for mosquitoes were approximately $0.5 \mathrm{~m}$ in diameter with an opening 20 $\mathrm{cm}$ wide. At each location, 9 OCPs were used for trapping outdoor resting mosquitoes in 3 dwellings each one separated by approximately $200-300 \mathrm{~m}$. Per dwelling, a set of 3 OCPs were placed outside in a radius of 1-5 $\mathrm{m}$ from the houses, with the opening mouth directed away from sunlight. Five to ten liters of water were poured into each pot to keep it moist during the two consecutive nights of sampling. OCPs were placed at 18:00 h and left overnight. OCPs were then visited every morning between 7:00 and 8:00 h and mosquitoes found inside the pots were collected with mouth aspirators and transferred into paper cups for subsequent analyses.

WETs were set up from 18:00 to 7:00 h to collect mosquitoes that attempted to escape from bedrooms. Per location, 10 rooms were selected and equipped with WETs adapted from the model developed by Muirhead-Thomson [23, 24]. WETs were placed over the window of each selected bedroom and left overnight for 2 consecutive days. Mosquitoes were then collected from each trap every morning between 7:00 and 9:00 $\mathrm{h}$ using a mouth aspirator, and transferred in paper cups for further analyses.

ISCs were performed once between 6:00 and 9:00 $\mathrm{h}$ in rooms used for WETs. After covering the entire floor space and objects with white sheets, the rooms were then sprayed with commercial aerosols containing deltamethrin insecticide and closed for 10-15 min. Mosquitoes that fell on the sheets were picked up, counted and individually preserved on silica gel in tubes.

For larval collections, anopheline larvae and pupae samples were collected by dipping from active breeding sites [20]. Each year, samples were pooled per study site and brought to a local insectary rearing conditions, until $\mathrm{F}_{0}$ adult emergence.

\section{Mosquito processing}

Adult specimens were morphologically identified using keys for the species of the genus Anopheles [17], and An. rufipes were separated from other local anopheline species by checking its typical characters on wings, legs and maxillary palp [25]. Members of the An. gambiae complex found in sympatry with $A n$. rufipes were identified using PCR methods [26]. The physiological status of Anopheles samples was visually assessed as "blood-fed", "gravid", "half gravid" or "unfed". All Anopheles specimens were screened for $P$. falciparum circumsporozoite protein (CSP) [27, 28] and for blood meal origin (if freshly fed Anopheles samples) by ELISA methods [29, 30]. For the latter, monoclonal antibodies against human, cow, pig, horse, chicken and sheep blood were used.

\section{Insecticide susceptibility testing}

Susceptibility of adult An. rufipes mosquitoes to deltamethrin was assessed using WHO test kits and standard procedures [31]. Test kits including impregnated papers, test tubes and accessories were purchased from the WHO reference center at the Vector Control Research Unit, University Sains Malaysia. Insecticide susceptibility tests were performed on $F_{0}$ females that emerged from aquatic stages (larvae and pupae). Batches of 20-25 two- to four-days-old unfed $A n$. 
rufipes were exposed to filter papers impregnated with $0.05 \%$ deltamethrin. Another batch was at the same time exposed to untreated filter papers to serve as a control. The number of knocked down mosquitoes was recorded during exposure $(60 \mathrm{~min})$, and then tested mosquitoes were transferred to holding tubes with cotton pads soaked with $10 \%$ sugar to determine the mortality $24 \mathrm{~h}$ post-exposure. Susceptibility tests were concomitantly performed with the Kisumu susceptible reference strain of An. gambiae (s.s.).

\section{Data analysis}

The circumsporozoite infection rate was calculated as the proportion of mosquitoes tested positive for $P$. falciparum circumsporozoite protein by ELISA. The overall human blood index (HBI) was determined as the proportion of mosquitoes identified to have fed on human blood by ELISA, i.e. included all mosquito samples positive for human blood meals either alone or mixed with other blood meals (undetermined blood sources were not considered). For each susceptibility test, the mortality rate was calculated as the proportion of dead mosquitoes over the total number of exposed specimens, when $<5 \%$ mortality was recorded in the control replicates. In the cases where the control mortality was $\geq 5 \%$ but $<20 \%$, the mortality rate of tested samples was adjusted using Abbott's formula [32]. Resistance status was evaluated according to the WHO criteria [31]. Knockdown times for 50 and 95\% $\left(\mathrm{KDT}_{50}\right.$ and $\left.\mathrm{KDT}_{95}\right)$ An. rufipes tested mosquitoes were estimated using a $\log$ probit model performed with WINDL software (version 2.0, 1999). The recorded $\mathrm{KDT}_{50}$ were compared with that of the Kisumu reference susceptible strain by estimates of $\mathrm{KDT}_{50}$ Ratios $\left(\mathrm{KDT}_{50} \mathrm{R}\right)$. For the statistical analysis, data were analyzed using Chisquare tests of the free online statistic tools of AnaStats 2016. The level of significance was $\alpha=0.05$.

\section{Results}

Anopheline density and distribution

A total of 9327 adult Anopheles were collected during 4 successive years (2011-2014) using the three sampling methods, among which 609 An. rufipes individuals were identified (6.5\%) alongside An. gambiae ( $s$. l.) (71.8\%) and An. funestus (s.l.) (20.8\%) (Table 1).
Six other species represented less than 1\% (81/9327) of total samples i.e. An. pharoensis, An. paludis, An. ziemanni, An. coustani, An. nili and An. longipalpis. Anopheles rufipes samples was identified across 35 of 38 selected study locations (including 3 locations positive at larval stages) (Fig. 2).

\section{Resting behavior}

The proportion of An. rufipes samples resting in outdoor pots was 51.2 vs $22.0 \%$ of those entering houses before resting indoors $\left(\chi^{2}=70.244, d f=1, P<0.001\right)$. As shown in Table 1 and compared with main vector species, An. rufipes [as An. funestus (s.l.)] showed a consistent propensity to rest outdoors than An. gambiae (s.l.) $\left(\chi^{2}=130.561, d f=1, P<0.001\right)$. This observation was enhanced by the high percentage of An. rufipes samples attempting to escape through WET (54.9\%) after entering houses compared with that of An. funestus $\left(\chi^{2}=85.412, d f=1, P<0.001\right)$.

\section{Blood-feeding status and indices}

In total 581 An. rufipes samples were checked for their feeding status, among which 379 (65.2\%) were blood-fed, $125(21.5 \%)$ unfed and 77 (13.3\%) gravid and/or halfgravid. The highest percentage of blood-fed samples was recorded in WET (74.9\%), followed by those collected by ISCs $(64.0 \%)$ and in oudoor pots $(60.5 \%)$, respectively This seems to be positively correlated with the exophilic habits of this vector species.

A total of 329 blood samples from An. rufipes were checked for blood meal origins, and 22 different blood meal combinations were recorded. About 18.5\% ( $n=61$ ) blood meals were exclusively from human origin, $12.8 \%(n=42)$ were a mixture of human and animals, $30.1 \%(n=99)$ were from five single animal hosts including cows (14.3\%), sheep (11.6\%), pigs (4\%) , chickens and horses, $24.3 \%(n=80)$ were a mixture blood meals taken from two or more animal hosts and $14.3 \%(n=47)$ were undetermined (Fig. 3).

The overall human blood index of An. rufipes was $37 \%$ with insignificant variations between indoor (53\%), outdoor (35\%) and window exiting (33\%) samples $\left(\chi^{2}=4.801, d f=2, P=0.0907\right)$ (Table 2). This suggests plasticity in resting and feeding behavior

Table 1 Number ( $n$ ) and frequency (\%) of Anopheles rufipes and other anophelines collected by three conventional methods from study districts of the North Cameroon

\begin{tabular}{|c|c|c|c|c|c|c|c|c|c|c|c|c|}
\hline \multirow{2}{*}{$\begin{array}{l}\text { Sampling } \\
\text { methods }\end{array}$} & \multicolumn{2}{|c|}{ An. rufipes } & \multicolumn{2}{|c|}{ An. gambiae (s.l.) } & \multicolumn{2}{|c|}{ An. funestus } & \multicolumn{2}{|c|}{ An. pharoensis } & \multicolumn{2}{|c|}{ Anopheles sp. } & \multicolumn{2}{|c|}{ Total anophelines } \\
\hline & $\bar{n}$ & $\%$ & $n$ & $\%$ & $\bar{n}$ & $\%$ & $n$ & $\%$ & $n$ & $\%$ & $n$ & $\%$ \\
\hline $\mathrm{OCP}$ & 312 & 3.35 & 1787 & 19.16 & 1231 & 13.20 & 11 & 0.12 & 13 & 0.14 & 3354 & 35.96 \\
\hline WETS & 163 & 1.75 & 2400 & 25.73 & 174 & 1.87 & 21 & 0.23 & 10 & 0.11 & 2768 & 29.68 \\
\hline ISCs & 134 & 1.44 & 2509 & 26.90 & 536 & 5.75 & 17 & 0.18 & 9 & 0.10 & 3205 & 34.36 \\
\hline Total/species & 609 & 6.53 & 6696 & 71.79 & 1941 & 20.81 & 49 & 0.53 & 32 & 0.34 & 9327 & 100 \\
\hline
\end{tabular}




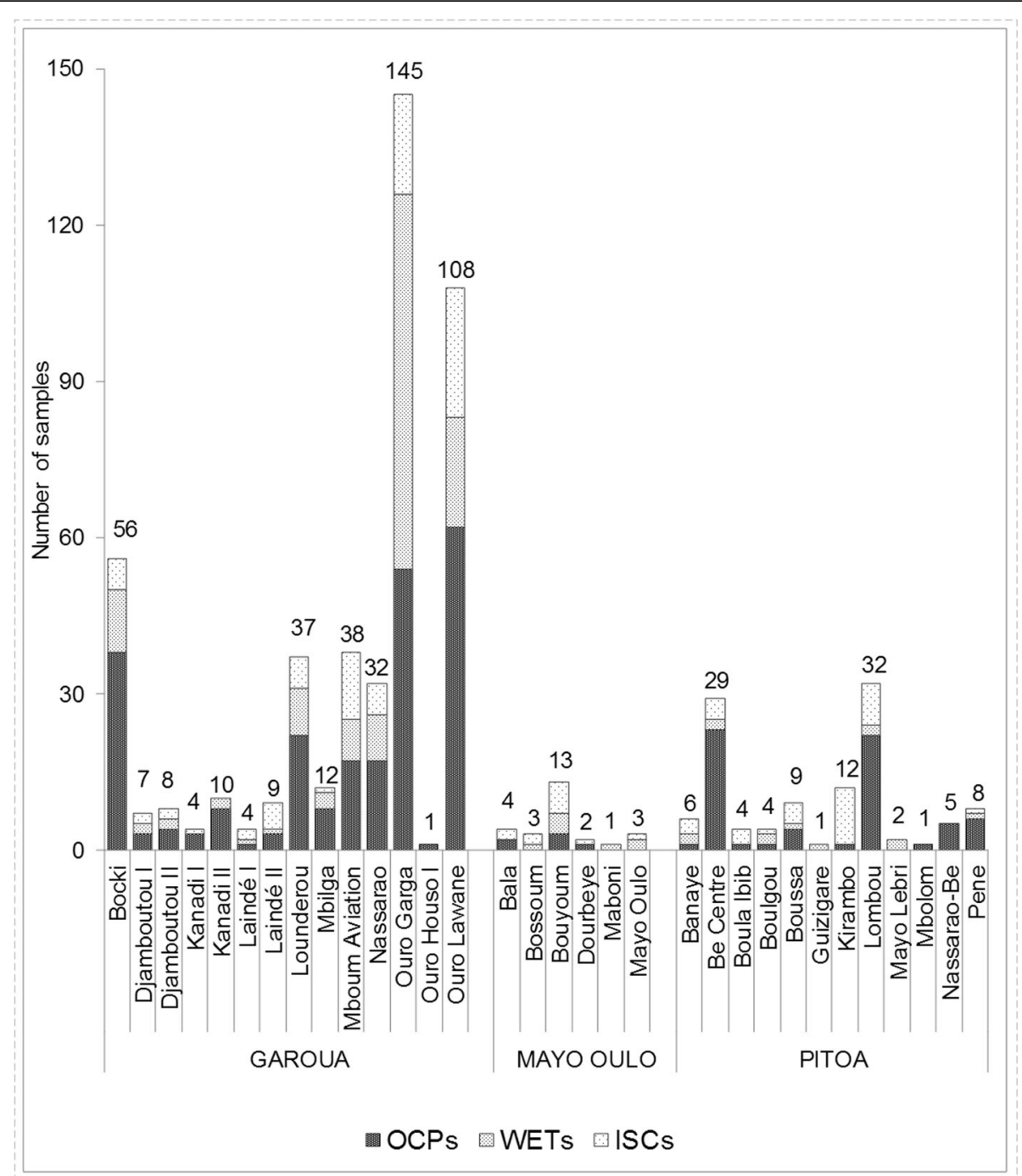

Fig. 2 Overall number of adult Anopheles rufipes mosquitoes collected using three sampling methods in 32 study locations of North Cameroon

developed by An. rufipes populations from study locations. As shown in Table 2, blood indices of each animal host also displayed variations either by vector species or by resting places.

\section{Malaria parasite infection}

The ELISA screening for the presence of Plasmodium circumsporozoite protein found two positive individuals (0.39\%) among 517 An. rufipes tested. This species contributed for less than $2 \%$ of the global CSP infection rate of $1.26 \%( \pm 0.23 \%)$, dominated by $A n$. gambiae (s.l.) ( 90\%) (Table 3).

\section{Status of susceptibility to deltamethrin}

Between 2012 and 2015, 21 bioassays were performed (Table 4). In all, susceptibility tests were performed on a total of 1092 female An. rufipes representing 59, 198 and 835 samples from Pitoa, Garoua and Mayo Oulo health districts, respectively. The recorded $\mathrm{KDT}_{50}$, $\mathrm{KDT}_{95}$ and $\mathrm{KDT}_{50} \mathrm{R}$ are presented in Table 4 and the mortality rates in Fig. 4.

Seven An. rufipes populations from six locations (Nassarao, Lounderou, Batoum, Bossoum, Kirambo and Nassarao-Be) revealed susceptible to deltamethrin (100\% mortality) with $\mathrm{KDT}_{50}$ and $\mathrm{KDT}_{95}$ ranges of 5 . 4-21.6 and 40.0-46.1 $\mathrm{min}$ respectively $(0.57 \leq$ $\mathrm{KDT}_{50} \mathrm{R} \leq 2.27$ ). Four An. rufipes populations in 4 different locations (Kanadi, Maboni, Doumo and Mboum aviation) showed resistance to deltamethrin (mortality from 80.8 to $88.7 \%$ ), with $\mathrm{KDT}_{50}$ and $\mathrm{KDT}_{95}$ ranges of $22.6-35.2$ and $37.2-80.2 \mathrm{~min}$, respectively $\left(2.38 \leq \mathrm{KDT}_{50} \mathrm{R} \leq 3.71\right)$. Finally, $10 \mathrm{An}$. rufipes populations from 8 clusters (Nassarao, Batoum, Boyoum, Bocki, Matra, Banaye, Bossoum and Dourbeye) showed probable resistance (from 91.6 to $97.8 \%$ mortality) with $\mathrm{KDT}_{50}$ and $\mathrm{KDT}_{95}$ ranges of 13 . 


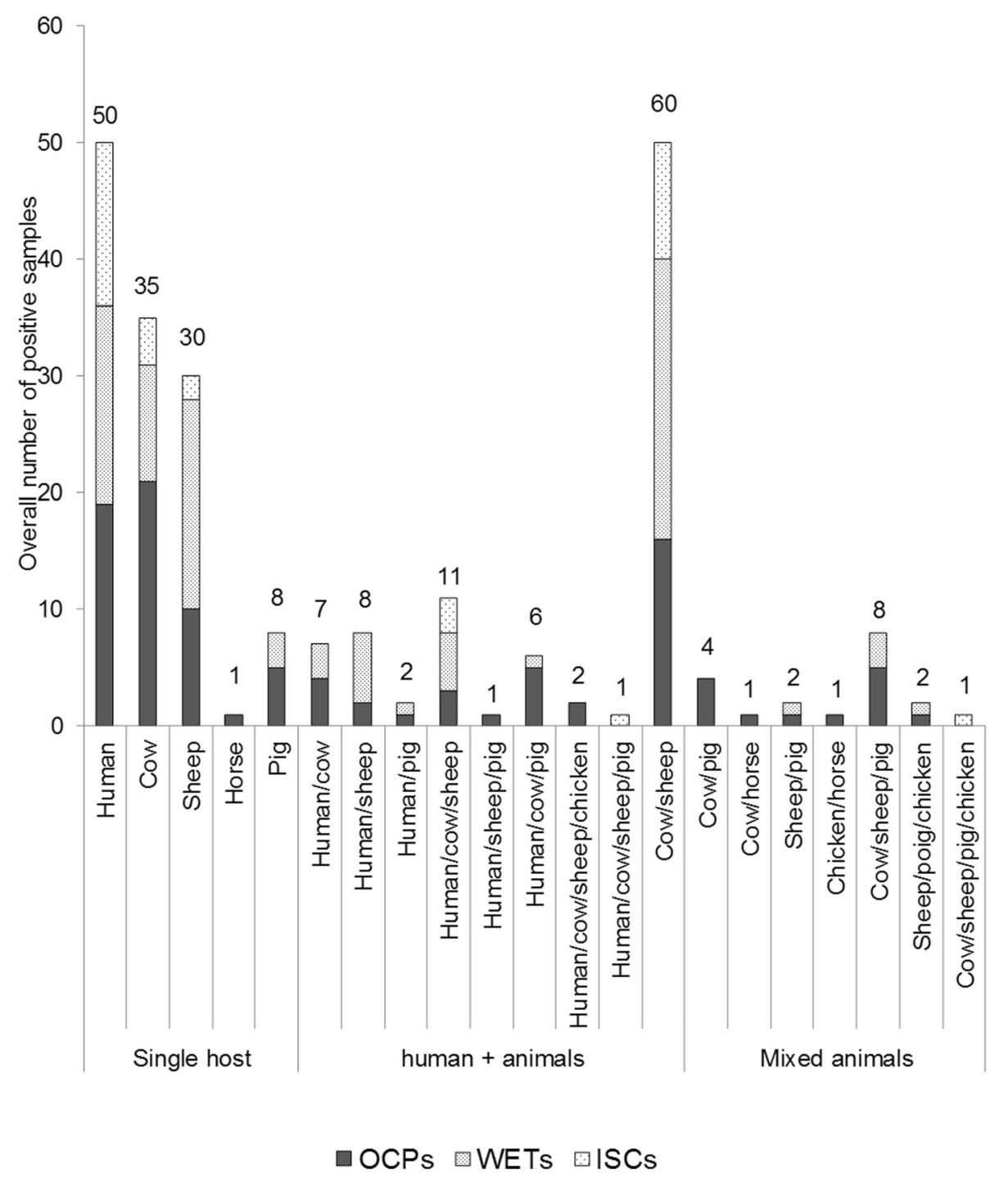

Fig. 3 Blood meal composition of Anopheles rufipes collected in 2012 and 2013 in selected health districts of North Cameroon

9-30.7 and 39.7-68.7 $\mathrm{min}$, respectively $(1.46 \leq$ $\left.\mathrm{KDT}_{50} \mathrm{R} \leq 3.23\right)$.

The trends in mortality rates ( \pm standard deviation) of $A n$. rufipes showed unpredictable variations across locations and years of collection. Deltamethrin susceptibility among populations was more distributed in 2014, with four "susceptible" populations and three remaining populations classified "probably resistant", compared with year 2013 with two susceptible populations, three ranged as "probably resistant" and three as "resistant", and year 2015 with no susceptible population out of five tested. In addition, $A n$. rufipes populations from Nassarao (2012 and 2013), Bossoum and Batoum (2013, 2014 and 2015) displayed changes on their status from "susceptible" one year to "probably resistant" another year and vice versa.

\section{Discussion}

The present paper is complimentary to a recently published paper which highlighted for the first time in Cameroon the important epidemiological role of An. rufipes in malaria transmission, with $0-0.481$ infectious bites/person/night recorded in study locations [12]. Few reports from western and southern Africa [32-37] are in accordance with this recent studies conducted so far in Cameroon.

The study objective was to present additional information on An. rufipes populations from the North Cameroon with a focus on its resting and feeding behaviors as well as on its susceptibility to deltamethrin insecticide after the nationwide distribution of LLINs in Cameroon in 2011. From the study, it appeared that $A n$. rufipes was widely distributed in both suburban and rural locations in the study area, concomitant with 
Table 2 Overall human and animal blood indices of Anopheles rufipes and main anopheline species from 2011 to 2014 in North Cameroon

\begin{tabular}{|c|c|c|c|c|c|c|c|}
\hline Species & Method & Human & Cow & Sheep & Pig & Chicken & Horse \\
\hline \multirow[t]{4}{*}{ An. rufipes } & $\mathrm{OCP}(n=143)$ & 0.35 & 0.55 & 0.41 & 0.20 & 0.03 & 0.02 \\
\hline & WET $(n=103)$ & 0.33 & 0.50 & 0.60 & 0.15 & 0.01 & 0.00 \\
\hline & ISC $(n=36)$ & 0.53 & 0.53 & 0.47 & 0.06 & 0.03 & 0.00 \\
\hline & Total $(n=282)$ & 0.37 & 0.52 & 0.49 & 0.16 & 0.02 & 0.01 \\
\hline \multirow[t]{4}{*}{ An. gambiae (s.l.) } & $\mathrm{OCP}(n=236)$ & 0.62 & 0.40 & 0.40 & 0.12 & 0.03 & 0.00 \\
\hline & WET $(n=159)$ & 0.85 & 0.22 & 0.16 & 0.09 & 0.04 & 0.00 \\
\hline & ISC $(n=689)$ & 0.69 & 0.30 & 0.25 & 0.10 & 0.03 & 0.01 \\
\hline & Total $(n=1084)$ & 0.70 & 0.31 & 0.27 & 0.11 & 0.03 & 0.01 \\
\hline \multirow[t]{4}{*}{ An. funestus } & $\mathrm{OCP}(n=240)$ & 0.35 & 0.54 & 0.57 & 0.19 & 0.01 & 0.00 \\
\hline & WET $(n=25)$ & 0.36 & 0.64 & 0.40 & 0.04 & 0.08 & 0.08 \\
\hline & ISC $(n=165)$ & 0.25 & 0.44 & 0.69 & 0.16 & 0.01 & 0.02 \\
\hline & Total $(n=430)$ & 0.31 & 0.51 & 0.60 & 0.17 & 0.01 & 0.01 \\
\hline
\end{tabular}

Abbreviation: $n$ number tested positive (undetermined not included)

known major malaria vector species of the An. gambiae complex (An. arabiensis, An. gambiae and An. coluzzii), An. funestus (s.s.) and An. pharoensis. This composition of resting individuals of malaria vectors has been frequently reported from savanna villages in Cameroon [7, $38]$ and elsewhere in Africa [36, 37, 39, 40]. This composition of resting vector populations does not necessarily reflect the relative abundance of a given species in the field; species including An. rufipes have displayed high and significant numbers of resting samples compared with that collected on human volunteers in same location in Senegal [39] and Chad [40]. Normally, Anopheles rufipes breed in various standing water bodies including marshes, pools, rice fields, river banks, temporary streams locally called "Mayos" which are also prolific, most especially for An.gambiae (s.l.) larval development.

An. rufipes was found to be highly opportunistic regarding its feeding and resting habits; this species was found to feed on a large variety of hosts including human, cows, sheep, pigs, chickens, horses and potentially other undetermined animals [12]. This observation was confirmed by our findings showing that, in the presence of alternative hosts, An. rufipes were less anthrophagic than zoophagic, about $37 \%$ of it blood meals were from human while up to $50 \%$ were from animals $(P<0.001)$. However, the preferred animal hosts were cows, sheep and pigs. This zoophagic propensity of An. rufipes is not uncommon and has been reported previously in the field [17]. Meanwhile, the combination of various blood meal origins, including human and animal hosts, is not unusual and has also been reported in well-known malaria vector species such as members of the An. gambiae complex, An. funestus and An. pharoensis in Cameroon $[19,38]$ and other tropical African countries [41-43].

Concerning the resting behavior, the sampling methods used have been previously applied as standards to sample mosquitoes resting around and inside human dwellings [44-47]. Based on this distribution in sampling methods, An. rufipes exhibited endophilic and exophilic behaviour in the study sites, consistent with flexibility observed in the local malaria vectors species $A n$. arabiensis, An. funestus and An. pharoensis. The best example of this behavioral plasticity is the widespread African malaria vector species, Anopheles arabiensis, which is capable of adapting its feeding responses according to various situations by feeding on human outdoors or on alternative animal hosts [48]. Any species

Table 3 Rate of Plasmodium falciparum circumsporozoite protein positivity (CSP+) of Anopheles rufipes and other malaria vector species by sampling methods from 2011 to 2014 in North Cameroon

\begin{tabular}{|c|c|c|c|c|c|c|c|c|c|}
\hline \multirow[t]{2}{*}{ Sampling method } & \multicolumn{3}{|c|}{ An. rufipes } & \multicolumn{3}{|c|}{ An. gambiae (s.l.) } & \multicolumn{3}{|c|}{ An. funestus } \\
\hline & Tested & $\mathrm{CSP}+$ & $\%(95 \% \mathrm{Cl})$ & Tested & $\mathrm{CSP}+$ & $\%(95 \% \mathrm{Cl})$ & Tested & CSP+ & $\%(95 \% \mathrm{Cl})$ \\
\hline$\overline{O C P}$ & 258 & 1 & $0.39(0.34-0.44)$ & 1773 & 18 & $1.02(1.01-1.03)$ & 1223 & 3 & $0.25(0.24-0.26)$ \\
\hline WETs & 143 & 1 & $0.70(0.59-0.81)$ & 2386 & 26 & $1.09(1.08-1.10)$ & 169 & 0 & 0 \\
\hline ISCs & 116 & 0 & - & 2466 & 59 & $2.39(2.38-2.40)$ & 528 & 5 & $0.95(0.91-0.99)$ \\
\hline Total & 517 & 2 & $0.39(0.37-0.41)$ & 6625 & 103 & $1.56(1.55-1,57)$ & 1920 & 8 & $0.42(0.41-0.43)$ \\
\hline
\end{tabular}


Table 4 Knockdown times (KDT 50 and $\left.K D T_{95}\right)$ and $\mathrm{KDT}_{50}$ ratios $\left(\mathrm{KDT}_{50} \mathrm{R}\right)$, following exposure to $0.05 \%$ deltamethrin of Anopheles rufipes (s.l.) populations from study locations of North Cameroon from 2012 to 2015

\begin{tabular}{|c|c|c|c|c|c|c|c|}
\hline Year & Health district & Location & $n$ & $\mathrm{KDT}_{50}(95 \% \mathrm{Cl})(\mathrm{min})$ & $\mathrm{KDT}_{95}(95 \% \mathrm{Cl})(\mathrm{min})$ & $\mathrm{KDT}_{50}$ ratio & Status \\
\hline 2012 & Garoua & NAS & 48 & $17.5(15.4-19.4)$ & $42.0(36.5-51.0)$ & 1.84 & S \\
\hline \multirow[t]{8}{*}{2013} & \multirow[t]{4}{*}{ Garoua } & Kanadi & 22 & $22.6(20.3-25.0)$ & $37.2(34.2-46.5)$ & 2.38 & $\mathrm{R}$ \\
\hline & & Lounderou & 28 & $21.6(19.1-24.0)$ & $40.2(34.9-47.9)$ & 2.27 & S \\
\hline & & Mboum Aviation & 26 & $35.2(31.7-38.6)$ & $70.2(60.6-87.9)$ & 3.71 & $\mathrm{R}$ \\
\hline & & Nassarao & 12 & $24.6(21.2-28.2)$ & $39.8(33.6-54.7)$ & 2.59 & SR \\
\hline & \multirow[t]{4}{*}{ Mayo Oulo } & Batoum & 80 & $21.3(19.3-23.2)$ & $54.5(48.3-63.7)$ & 2.24 & SR \\
\hline & & Bossoum & 32 & $21.5(18.2-24.5)$ & $53.0(44.5-69.1)$ & 2.26 & S \\
\hline & & Boyoum & 87 & $25.0(23.4-26.6)$ & $55.9(50.6-63.4)$ & 2.63 & SR \\
\hline & & Maboni & 51 & $32.4(29.7-35.5)$ & $80.2(68.2-100.4)$ & 3.41 & $\mathrm{R}$ \\
\hline \multirow[t]{7}{*}{2014} & Garoua & Bocki & 62 & $21.9(20.1-23.7)$ & $48.3(43.0-56.2)$ & 2.31 & SR \\
\hline & \multirow[t]{3}{*}{ Mayo Oulo } & Batoum & 107 & $9.9(9.0-10.7)$ & $27.0(24.1-30.9)$ & 1.04 & S \\
\hline & & Bossoum & 43 & $18.0(15.2-20.5)$ & $39.4(34.0-48.7)$ & 1.90 & S \\
\hline & & Matra & 90 & $21.2(19.8-22.7)$ & $51.3(46.2-58.4)$ & 2.23 & $S R$ \\
\hline & \multirow[t]{3}{*}{ Pitoa } & Banaye & 20 & $13.9(8.3-18.1)$ & $39.7(31.2-61.0)$ & 1.46 & $S R$ \\
\hline & & Kirambo & 26 & $10.5(4.6-15.7)$ & $41.5(30.8-63.2)$ & 1.11 & S \\
\hline & & Nassarao-Be & 13 & $5.4(0.8-10.9)$ & $46.1(25.5-174.8)$ & 0.57 & S \\
\hline \multirow[t]{5}{*}{2015} & \multirow[t]{5}{*}{ Mayo Oulo } & Batoum & 21 & $27.5(24.1-31.2)$ & $60.1(49.9-80.5)$ & 2.90 & $S R$ \\
\hline & & Bossoum & 67 & $23.7(22.1-25.4)$ & $49.1(44.3-56.1)$ & 2.50 & $S R$ \\
\hline & & Boyoum & 89 & $28.0(26.2-29.8)$ & $65.1(58.4-74.5)$ & 2.95 & SR \\
\hline & & Doumo & 97 & $26.6(21.4-23.8)$ & $45.4(41.7-50.3)$ & 2.80 & $\mathrm{R}$ \\
\hline & & Dourbeye & 71 & $30.7(28.3-33.0)$ & $68.7(60.8-80.8)$ & 3.23 & SR \\
\hline
\end{tabular}

Abbreviations: $n$ number tested, $C l$ confidence interval, $S$ susceptible, $S R$ suspected resistance to be confirmed, $R$ resistance

with such behavioural heterogeneity in the field should be regarded as a potential target for the control of residual malaria parasite transmission [49].

More importantly, two An. rufipes specimens were found positive for CSP, one from Ouro Lawane in $2013(n=38)$ and one from Lombou in 2014 $(n=$ 17). This finding confirms the ability of this species to carry human malaria parasites, as it has been also demonstrated in a parallel study on transmission profiles carried out in the same locations [12]. This further observation is remarkable since several authors ranked this species as zoophilic, with very little or no epidemiological importance in some areas. The screening of the presence of malaria infection in mosquitoes was continuously improved since the first evidence of sporozoites in a single An. rufipes specimen 60 years ago to date with the detection of parasite antigens by ELISA and PCR methods. These advanced techniques frequently detect as positive for Plasmodium sporozoites several species that are not considered vectors, and provide little indication of the transmission ability of such species [50-54]. Based on these observations, An. rufipes could henceforth be considered as a potential vector in North Cameroon, indicating that it should also be considered during monitoring along with other malaria vector species of the vectorial system.

Furthermore, by assessing for the first time the susceptibility of An. rufipes populations to deltamethrin, one of the common pyrethroid insecticides used in LLINs distributed nationwide in 2011 and in 2016 in Cameroon, we observed that mortality rates were highly variable depending on the location and time point. The distribution of confirmed or suspected resistance in 12 of the 15 tested An. rufipes populations is indicative of the development of phenotypic resistance to pyrethroids in the three surveyed health districts. In addition to previous reports on pyrethroid resistance in members of the An. gambiae complex from the same locations $[19,55,56]$, these data highlight the extent of insecticide resistance in potential malaria vector populations from North Cameroon. This is the first report of pyrethroid resistance in An. rufipes from Cameroon, which may have a potential impact on the efficacy of LLINs in study health districts. Insecticide resistance in An. rufipes populations and other vector species of An. gambiae complex and An. funestus group from this region should therefore be hence 


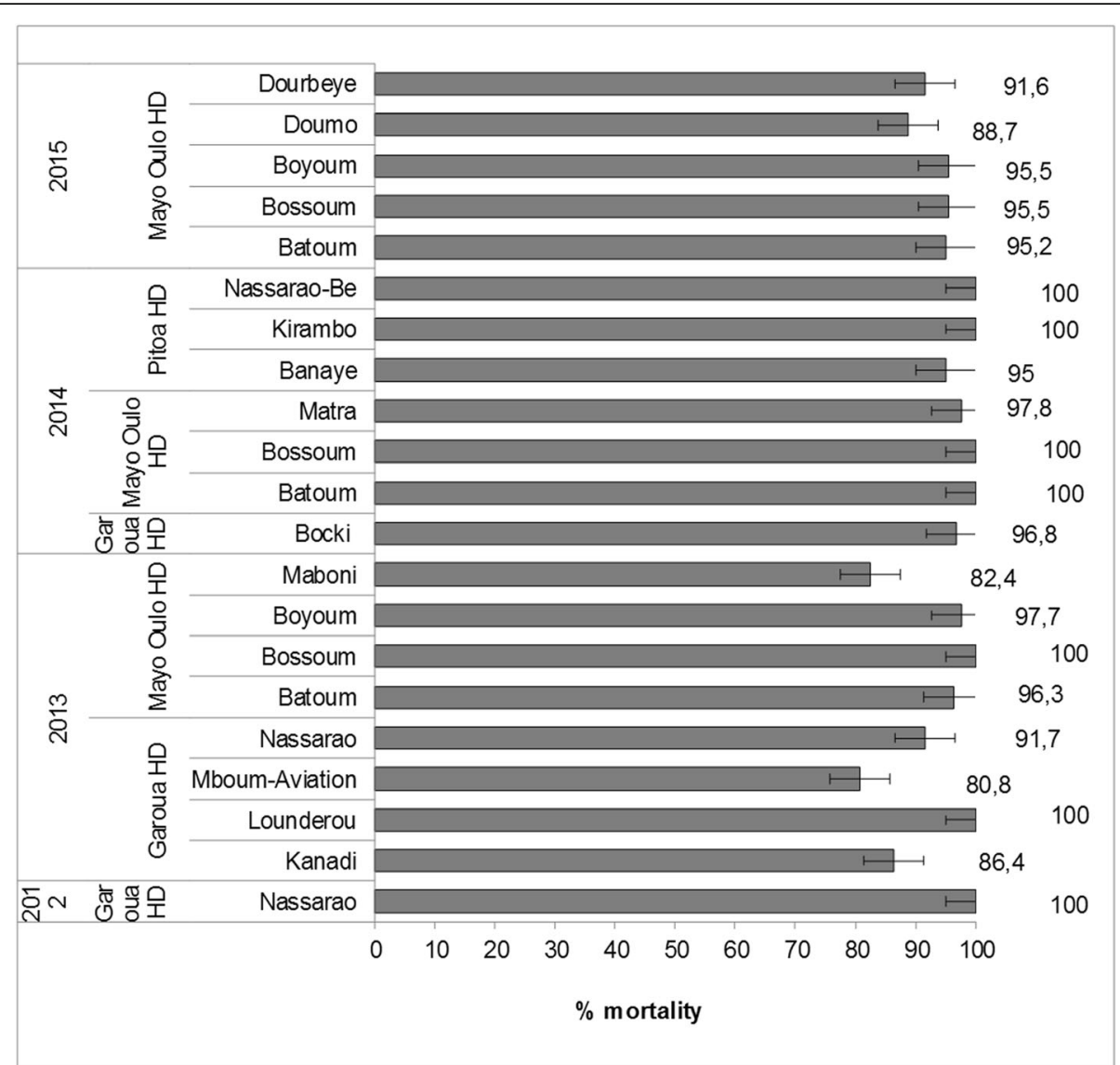

Fig. 4 Mortality rates (\%) following exposure to $0.05 \%$ deltamethrin impregnated papers of Anopheles rufipes populations from Garoua, Pitoa and Mayo Oulo Health Districts collected between 2012 and 2015

monitored according to the new WHO guidelines [57], in order to guide comprehensive and data-driven planning and implementation of vector control.

\section{Conclusions}

The current study gathered relevant information on the resting and feeding behavior and deltamethrin susceptibility of An. rufipes populations from North Cameroon relative to other malaria vectors, and confirmed that this species may have a potential role in local malaria epidemiology. The findings indicate that An. rufipes should be considered in monitoring programs for malaria vectors in North Cameroon, and potentially throughout the tropical domain of African countries.

\section{Abbreviations}

CSP: circumsporozoite protein; ELISA: enzyme-linked immunosorbent assay; ISCs: indoor spraying catches; KDT: knockdown times; LLINs: long-lasting insecticidal treated nets; OCPs: outdoor clay pots; WETs: window exit traps; WHO: World Health Organization

\section{Acknowledgements}

The authors acknowledge administrative and health authorities for their assistance during field collections as well as populations in the study locations of Garoua, Pitoa and Mayo Oulo Health Districts for their collaboration.

\section{Funding}

This study received financial support from the Bill and Melinda Gates Foundation (Grant Number: 48499101). This research forms part of a multicountry study coordinated by the Global Malaria Programme of the World Health Organization.

\section{Availability of data and materials}

Data supporting the conclusions of this article are included within the article. The datasets generated and material analyzed during the current study are available at the OCEAC Research Institute of Yaounde, No. 888 Road 2003

Yaounde 2, Cameroon under the responsibility of the corresponding author.

\section{Authors' contributions}

PAA, JE, EF, TBK, APM, MJD and JB conceived and planned the study and its design. PAA, JE, CN, WEE, MCP, ESM, LRM, JCT and SP monitored the field and laboratory studies. PAA and JE drafted the manuscript, analyzed and interpreted the data. CAN, TBK, APM, MJD and JB reviewed and helped write the manuscript. All authors read and approved the final manuscript.

Ethics approval and consent to participate

Access to houses and bedrooms for mosquito collections was subject to approval from household owners and community leaders. An ethical clearance was obtained from the National ethics committee of Cameroon under the reference number FWA IRB00001954 and approved through the authorization number 102/CNE/SE/09.

Consent for publication

Not applicable. 


\section{Competing interests}

The authors declare that they have no competing interests.

\section{Publisher's Note}

Springer Nature remains neutral with regard to jurisdictional claims in published maps and institutional affiliations.

\section{Author details}

${ }^{1}$ Research Institute of Yaounde (IRY), Organization de Coordination pour la lutte contre les Endémies en Afrique Centrale (OCEAC), B.P. 288, Yaoundé, Cameroon. ${ }^{2}$ Department of Biological Sciences, Faculty of Medicine and Pharmaceutical Sciences, University of Douala, P.O. Box 2701, Douala, Cameroon. ${ }^{3}$ Faculty of Sciences, University of Douala, P.O. Box 2701, Douala, Cameroon. ${ }^{4}$ Ecole des Sciences de la Santé, Université Catholique d'Afrique Centrale, B.P. 1110, Yaoundé, Cameroon. ${ }^{5}$ Faculty of Sciences, University of Yaoundé I, P.O. Box 812, Yaounde, Cameroon. ${ }^{6}$ National Malaria Control Programme, Ministry of Public Health, P.O. Box 14386, Yaoundé, Cameroon. ${ }^{7}$ The African Leaders Malaria Alliance (ALMA), 3 Barack Obama Drive, P.O. Box 70198, 11101 Dar es Salaam, Tanzania. ${ }^{8}$ Global Malaria Programme, World Health Organization, Avenue Appia, Geneva, Switzerland. ${ }^{9}$ Department of Vector Biology, Liverpool School of Tropical Medicine, Pembroke Place, Liverpool L3 5QA, UK. ${ }^{10}$ National Reference Unit for Vector Control, The Biotechnology Center, University of Yaoundé I, P.O. Box 3851-Messa, Yaoundé, Cameroon.

\section{Received: 3 November 2017 Accepted: 25 March 2018}

\section{Published online: 18 April 2018}

\section{References}

1. Hervy JF, Le Goff G, Geoffroy B, Herve JP, Manga L, Brunhes J. Les Anophèles de la région afro tropicale. Paris: ORSTOM Editions; 1998

2. WHO. World malaria report 2017. Geneva: World Health Organization; 2017.

3. Institut National de la Statistique. Annuaire Statistique du Cameroun. Yaounde: INS; 2015;7:119-78

4. MINSANTE. Plan stratégique National de lutte contre le paludisme au Cameroun 2014 -2018. Yaounde: Ministry of Health; 2016.

5. Coetzee M, Hunt RH, Wilkerson R, Della Torre A, Coulibaly MB, Besansky NJ. Anopheles coluzzii and Anopheles amharicus, new members of the Anopheles gambiae complex. Zootaxa. 2013;3619:246-74.

6. Fontenille D, Wandji S, Djouaka R, Awono-Ambene HP. Anopheles hancocki, vecteur secondaire du paludisme au Cameroun. Bull Liais Doc OCEAC. 2000 33:23-6.

7. Antonio-Nkonjio C, Kerah CH, Simard F, Awono-Ambene P, Chouaibou M, Tchuinkam T, et al. Complexity of malaria vectorial system in Cameroon: contribution of secondary vectors to malaria transmission. J Med Entomol. 2006:43:1215-21.

8. Awono-Ambene HP, Antonio Nkondjio C, Toto JC, Ndo C, Etang J, Fontenille D, et al. Epidemiological importance of the Anopheles nili group of malaria vectors in equatorial villages of Cameroon, Central Africa. Sci Med Africa. 2009:1:13-20.

9. Brunhes J, Le Goff G, Geoffroy B. Afro-tropical anopheline mosquitoes. III. Description of three new species: Anopheles carnevalei sp. nov., An. hervyi sp. nov., and An. dualaensis sp. nov., and resurrection of An. rageaui Mattingly \& Adam. J Am Mosq Control Assoc. 1999;15:552-8.

10. Awono-Ambene HP, Kengne P, Simard F, Antonio-Nkondjio C, Fontenille D. Description and bionomics of Anopheles (Cellia) ovengensis (Diptera: Culicidae), a new malaria vector species of the Anopheles nili group from south Cameroon. J Med Entomol. 2004;41:561-8.

11. Tabue RN, Nem T, Atangana J, Bigoga JD, Patchoke S, Tchouine F, et al. Anopheles ziemanni a locally important malaria vector in Ndop health district, North west region of Cameroon. Parasit Vectors. 2014;7:262.

12. Tabue RN, Awono-Ambene HP, Etang J, Atangana J, Antonio-Nkondjio C, Toto JC, et al. Role of Anopheles (Cellia) rufipes (Gough, 1910) and other local anophelines in human malaria transmission in the northern savannah of Cameroon: a cross sectional survey. Parasit Vectors. 2017;10:22.

13. Etang J, Manga L, Chandre F, Guillet P, Fondjo E, Mimpfoundi $R$, et al. Insecticide susceptibility status of Anopheles gambiae s.l. (Diptera: Culicidae) in the Republic of Cameroon. J Med Entomol. 2003:40:491-7.

14. Etang J, Manga L, Toto JC, Guillet P, Fondjo E, Chandre F. Spectrum of metabolic-based resistance to DDT and pyrethroids in Anopheles gambiae s. I. populations from Cameroon. J Vector Ecol. 2007;32:123-33.
15. Nwane P, Etang J, Chouaibou M, Toto JC, Kerah-Hinzoumbé C, Mimpfoundi $\mathrm{R}$, et al. Trends in DDT and pyrethroid resistance in Anopheles gambiae s.S. populations from urban and agro-industrial settings in southern Cameroon. BMC Infect Dis. 2009:9:163.

16. Nwane P, Etang J, Chouaibou M, Toto JC, Mimpfoundi R, Simard F. Kdrbased insecticide resistance in Anopheles gambiae s.s. populations in Cameroon: spread of the L1014F and L1014S mutations. BMC Res Notes. 2011;4:463.

17. Gillies MT, De Meillon B. The Anophelinae of Africa south of the Sahara (Ethiopian Zoogeographical Region). Johannesburg: South African Institute for Medical Research Institute; 1968. no. 54.

18. Menze BD, Riveron JM, Ibrahim SS, Irving H, Antonio-Nkondjio C, AwonoAmbene $\mathrm{PH}$, et al. Multiple insecticide resistance in the malaria vector Anopheles funestus from Northern Cameroon is mediated by metabolic resistance alongside potential target site insensitivity mutations. PLoS One. 2016;11:e0163261

19. Etang J, Pennetier C, Piameu M, Bouraima A, Chandre F, Awono-Ambene P, et al. When intensity of deltamethrin resistance in Anopheles gambiae s.l. leads to loss of long-lasting insecticidal nets bio-efficacy: a case study in north Cameroon. Parasit Vectors. 2016;9:132

20. Service MW. Mosquito ecology: field sampling methods. 2nd ed. London: Chapman \& Hall; 1993

21. Odiere M, Bayoh MN, Gimnig J, Vulule J, Irungu L, Walker E. Sampling outdoor, resting Anopheles gambiae and other mosquitoes (Diptera: Culicidae) in western Kenya with clay pots. J Med Entomol. 2007;44:14-22

22. Lardeux F, Loayza P, Bouchite B, Chavez T. Host choice and human blood index of Anopheles pseudopunctipennis in a village of the Andean valleys of Bolivia. Malar J. 2007:6:8

23. Muirhead-Thomson RC. The effects of houses praying with pyrethrum and with DDT on Anopheles gambiae and Anopheles melas in West Africa. Bull Entomol Res. 1947;38:449-64.

24. Muirhead-Thomson RC. Studies on Anopheles gambiae and Anopheles melas in and around Lagos. Bull Entomol Res. 1948;38:527-58.

25. Gimba UN, Idris HS. Morphological identification and distribution of Anopheles species in Gwagwalada Town, F.C.T, Nigeria. Int J Environ Sci Toxic Res. 2014:2(10):210-6.

26. Fanello C, Santolamazza F, Della TA. Simultaneous identification of species and molecular forms of the Anopheles gambiae complex by PCR-RFLP. Med Vet Entomol. 2002;16:461-4.

27. Burkot TR, Williams JL, Schneider I. Identification of Plasmodium falciparum infected mosquitoes by a double antibody enzyme linked immunosorbent assay. Am J Trop Med Hyg. 1984;33:783-8.

28. Wirtz RA, Zavala F, Charoenvit Y, Campbell GH, Burkot TR, Schneider I, et al. Comparative testing of Plasmodium falciparum sporozoite monoclonal antibodies for ELISA development. Bull World Health Organ. 1987:65:39-45.

29. Beier JC, Perkins PV, Wirtz RA, Koros J, Diggs D, Gargam TPIl, et al. Blood meal identification by direct enzyme-linked immunosorbent assay (ELISA) tested on Anopheles (Diptera: Culicidae) in Kenya. J Med Entomol. 1988;25:9-16.

30. Abbott WS. A method of computing the effectiveness of an insecticide. J Econ Entomol. 1925;18:265-7.

31. WHO. Test procedures for insecticide resistance monitoring in malaria vector mosquitoes. Geneva: World Health Organization; 2013.

32. Gelfand HM. Natural malaria infection in Anopheles rufipes (Gough). J Trop Med Hyg. 1947;50(8):159-60.

33. Holstein M. Un nouveau vecteur du paludisme en AOF: Anopheles rufipes Gough 1910. Off Rech Sci D'Outre-Mer. 1949;379:1-143.

34. De Meillon B. Species and varieties of malaria vectors in Africa and their bionomics. Bull WHO. 1951;4:419-41.

35. Holstein MH. Note sur l'épidémiologie du paludisme en Afrique-Occidentale Française. Bull WHO. 1951;4:463-73.

36. Da DF, Diabaté A, Mouline K, Lefèvre T, Awono-Ambene HP, Ouédraogo JB, et al. Anopheles rufipes remains a potential malaria vector after the first detection of infected specimens in 1960 in Burkina Faso. J Infect Dis Ther. 2013:1:112.

37. Lobo NF, St. Laurent B, Sikaala CH, Hamainza B, Chanda J, Chinula D, et al. Unexpected diversity of Anopheles species in Eastern Zambia: implications for evaluating vector behavior and interventions using molecular tools. Sci Rep. 2015;5:17952.

38. Antonio-Nkondjio C, Atangana J, Ndo C, Awono-Ambene P, Fondjo E, Fontenille $\mathrm{D}$, et al. Malaria transmission and rice cultivation in Lagdo, northern Cameroon. Trans R Soc Trop Med Hyg. 2008;102(4):352-9. 
39. Robert V, Dieng H, Lochouarn L, Traoré SF, Trape JF, Simondon F, et al. La transmission du paludisme dans la zone rurale de Niakhar, Sénégal. Trop Med Int Health. 1998;3:667-77.

40. Kérah-Hinzoumbé C, Mallaye P, Antonio-Nkondjio C, Awono-Ambene HP, Samè-Ekobo A, Simard F. Malaria vectors and transmission dynamics in Goulmoun, a rural city in south-western Chad. BMC Infect Dis. 2009;9:71.

41. Russell TL, Govella NJ, Azizi S, Drakeley CJ, Kachur SP, Killeen GF. Increased proportions of outdoor feeding among residual malaria vector populations following increased use of insecticide-treated nets in rural Tanzania. Malar J. 2011;10:80.

42. Massebo F, Balkew M, Gebre-Michael T, Lindtjørn B. Blood meal origins and insecticide susceptibility of Anopheles arabiensis from Chano in South-West Ethiopia. Parasit Vectors. 2013;6:44.

43. Lefèvre T, Gouagna LC, Dabiré KR, Elguero E, Fontenille D, Renaud F, et al. Beyond nature and nurture: phenotypic plasticity in blood-feeding behavior of Anopheles gambiae s.s. when humans are not readily accessible. Am J Trop Med Hyg. 2009:81(6):1023-9.

44. Okumu FO, Kotas ME, Kihonda J, Mathenge E, Killeen GF, Moore SJ. Comparative evaluation of methods used for sampling malaria vectors in the Kilombero Valley, South Eastern Tanzania. Open Trop Med J. 2008;1:51-5.

45. Service MW. A critical review of procedures for sampling populations of adult mosquitoes. Bull Entomol Res. 1977:67:343-82.

46. Govella NJ, Chaki PP, Mpangile JM, Killeen GF. Monitoring mosquitoes in urban Dar es Salaam: evaluation of resting boxes, window exit traps, CDC light traps, Ifakara tent traps and human landing catches. Parasit Vectors. 2011;4:40.

47. Wong J, Bayoh N, Olang G, Killeen GF, Hamel MJ, Vulule JM, et al. Standardizing operational vector sampling techniques for measuring malaria transmission intensity: evaluation of six mosquito collection methods in western Kenya. Malar J. 2013;12:14.

48. Killeen GF, Govella NJ, Lwetoijera DW, Okumu FO. Most outdoor malaria transmission by behaviourally-resistant Anopheles arabiensisis mediated by mosquitoes that have previously been inside houses. Malar J. 2016;15:225.

49. WHO. Guidance notes on the control of residual malaria transmission. Geneva: World Health Organization; 2014.

50. Pates HV, Takken W, Curtis CF, Huisman PW, Akinpelu O, Gill GS Unexpected anthropophagic behaviour in Anopheles quadriannulatus. Med Vet Entomol. 2001;15:293-8.

51. Pates HV, Takken W, Curtis CF, Jamet H. Zoophilic Anopheles quadriannulatus species B found in a human habitation in Ethiopia. Ann Trop Med Parasitol. 2006;100:177-9.

52. Okara RM, Sinka ME, Minakawa N, Mbogo CM, Hay SI, Snow RW. Distribution of the main malaria vectors in Kenya. Malar J. 2010;9:69.

53. Stevenson J, St. Laurent B, Lobo NF, Cooke MK, Kahindi SC, Oriango RM, et al. Novel vectors of malaria parasites in the western highlands of Kenya. Emerg Infect Dis. 2012;18:1547-9.

54. Kawada H, Dida GO, Sonye G, Njenga SM, Mwandawiro C, Minakawa N. Reconsideration of Anopheles rivulorum as a vector of Plasmodium falciparum in western Kenya: some evidence from biting time, blood preference, sporozoite positive rate, and pyrethroid resistance. Parasit Vectors. 2012:5:230.

55. Chouaïbou M, Etang J, Brevault T, Nwane P, Hinzoumbé CK, Mimpfoundi R, et al. Dynamics of insecticide resistance in the malaria vector Anopheles gambiae s.l. from an area of extensive cotton cultivation in Northern Cameroon. Tropical Med Int Health. 2008;13:1-11.

56. Nwane P, Etang J, Chouaïbou M, Toto JC, Koffi A, Mimpfoundi R, et al. Multiple insecticide resistance mechanisms in Anopheles gambiae s.l. populations from Cameroon, Central Africa. Parasit Vectors. 2013;6:41.

57. WHO. Test procedures for insecticide resistance monitoring in malaria vector mosquitoes. 2nd ed. Geneva: WHO; 2016.

\section{Submit your next manuscript to BioMed Central and we will help you at every step:}

- We accept pre-submission inquiries

- Our selector tool helps you to find the most relevant journal

- We provide round the clock customer support

- Convenient online submission

- Thorough peer review

- Inclusion in PubMed and all major indexing services

- Maximum visibility for your research

Submit your manuscript at www.biomedcentral.com/submit
C Biomed Central 